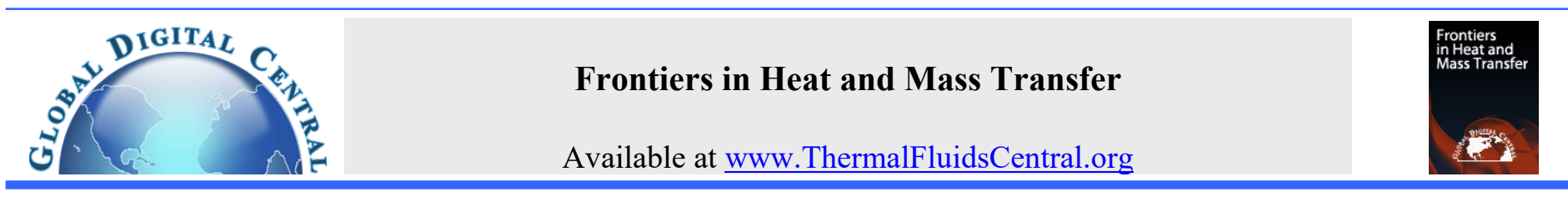

\title{
EFFECTS OF VISCOUS DISSIPATION AND AXIAL HEAT CONDUCTION ON FORCED CONVECTION FLOW OF HERSCHEL- BULKLEY FLUID IN CIRCULAR DUCT WITH AXIALLY VARIABLE WALL HEAT FLUX
}

\author{
Rabha Khatyr* and Jaafar Khalid Naciri \\ Laboratory of Mechanics, Faculty of Sciences Aïn Chock, B.P. 5366, Maarif, Hassan II University, Casablanca 20100, Morocco
}

\begin{abstract}
The present study focuses on the effects of viscous dissipation and axial heat conduction on the asymptotic behavior of the laminar forced convection in a circular duct for a Herschel-Bulkley fluid with variable wall heat flux. Analytical asymptotic solutions are presented for the case of axial variations of the wall heat flux, with finite non-vanishing values at infinity along the flow direction. The asymptotic bulk and mixing Nusselt numbers and the asymptotic bulk and mixing temperature distributions are evaluated analytically in the case of axially variable wall heat flux for which polynomial and logarithmic functions are considered as examples. It is shown that the asymptotic bulk Nusselt number depends on the dimensionless radius of the plug flow region $a$, on the power-law exponent $n$, on the Peclet number $P e$ and the asymptotic Brinkman number $B r_{\infty}$. The effects of yield stress, Peclet number, and Brinkman number on the asymptotic bulk Nusselt number are discussed.
\end{abstract}

Keywords: Laminar forced convection; Viscous dissipation; Herschel-Bulkley fluid; Analytical Methods; Asymptotic behavior.

\section{INTRODUCTION}

The forced convection of yield shear stress non-Newtonian fluids in pipes and channels is studied in many works considering the numerous industrial applications related to the physics of this type of flows. The interactions between hydrodynamics, heat transfer and fluid rheology generate very diverse configurations and studies usually limit their field of investigation by restricting the ranges of parameter variations. Among the restrictions generally introduced on 'heat transfer', there are those relating to the type of boundary conditions which generally assume either a uniform temperature or heat flux to the walls, or those which neglects axial conduction or viscous dissipation in the energy balance, or finally conditions on the thermally established nature of the flow.

Therefore, many solutions are obtained in the case of constant wall temperature or wall heat flux (see for Newtonian fluid (Aydin 2005, Aydin and Avci 2006, Haji-Sheikh 2009, Haji-Sheikh et al. 2009, Magyari and Barletta 2007, Mandapati 2016)), power-law fluid (Jambal et al. 2005), Bingham fluid (Min et al. 1997), and Herschel-Bulkley fluid (Sayed-Ahmed and Kishk 2008, Ditchfield et al. 2006, Da Silva 2014), although the temperature or the heat flux at the walls are variable in several practical situations (Sabry 2017).

For fully developed velocity profile laminar flow, several experiments have pointed out that the Nusselt number tends to become invariant along the flow direction under certain boundary conditions, not only in cases where the wall temperature or the wall heat flux is uniform but also for situations where the wall heat flux varies exponentially among others. Barletta and Zanchini (1996) and Barletta (1997) determined sufficient conditions for the existence of a fully thermally developed region in the cases where the wall of a pipe is subjected to various non-uniform axial distributions of wall heat flux, for Newtonian fluids (Barletta and Zanchini (1996-a)) and power-law fluids (Barletta and Zanchini (1996-b), Barletta (1997)).

A common practical case in which exponentially varying heat fluxes are encountered is the simple co-current or counter current heat exchanger. Gräber $(1968,1969,1970)$ studied the forced convection of a Newtonian fluid flowing in smooth tubes, between two parallel plates, along a flat plate, in annular spaces or along tubular bundles with wall heat flux distributions exponential or polynomial, which give a fully developed heat transfer coefficient, for laminar and turbulent flow with a linear pressure drop. He has shown (Gräber, 1969), by using similarity considerations, that in parallel flow along flat plate the fully developed temperature distribution based on thermal boundary layer thickness can only be expected for laminar flow and distribution of heat flux obeying the power law $q_{w} \sim x^{m}$.

The asymptotic temperature field and the asymptotic value of the Nusselt number are evaluated experimentally by Piva and Pagliarini (1994) in the case of exponential wall heat flux. The fully developed thermally region is studied analytically with both negligible viscous dissipation and axial conduction effects with exponential (Piva, 1995) and sinusoidal wall heat flux distribution (Barletta and Zanchini, 1995). The same work was carried out by Barletta and Zanchini (1999) and Zanchini (1997) for sinusoidal and other wall heat flux axial distributions and with viscous dissipation. The effect of axial conduction was examined analytically by Barletta et al. $(1995,2000)$ with exponential and sinusoidal wall heat flux.

Sabry (2017) gave a general analytic solution, which is valid for arbitrary wall boundary conditions and negligible viscous dissipation. The boundary conditions are developed in series (example for wall heat flux : $q_{w}(x)=\sum_{i=0}^{N} q_{w, i} x^{i}$ where the $q_{w, i}$ are constant). For a straight 
circular duct, this analysis has allowed analytical derivation of a simple relation giving thermal entrance length over tube diameter as a function of Peclet number.

In order to increase the heat transfer, various ways can be explored by introducing modifications to characteristics such as the nature of the fluid, the flow regime, the shapes of the walls or even by combinations of each of these properties. Thus, Yang et al. (2018) studied numerically turbulent convective heat transfer in an elliptical pipe. They obtained an empirical correlation between Nusselt number, Reynolds number and Prandtl number in the fully developed fluid section of the elliptical tube. Zhang et al. (2019) presented a numerical study of periodically fully developed flow and heat transfer in channels with periodic semi-circular tube. They showed that the Nusselt number progressively increases with decreasing tube spacing at the same Reynolds number. Another possibility that has been the subject of several works is the use of magnetic properties for nanofluids as has been studied by Singh et al. (2016), Pandey and Kumar (2017, 2018), Mishra et al. (2018, 2019), Nagaraju et al. (2019). Singh (2019) considered the micropolar fluid model to adequately describe the heat transfer to fluid with suspended particles.

In the present work, we consider the effect of non-Newtonian yield stress behavior on the rate of heat transfer. Khatyr et al. (2003) gave analytical solutions for fully developed laminar forced convection in circular ducts for a Bingham plastic with viscous dissipation and negligible axial heat conduction in the fluid with various axial distributions of wall heat flux. In Refs. (Khatyr et al. 2010, 2016), the authors gave analytical solutions for fully developed laminar forced convection in circular ducts for a Herschel-Bulkley fluid in a horizontal duct with neglected axial conduction and with various axial distributions of wall heat flux for which polynomial, exponential and logarithmic functions was considered as examples.

Khatyr et al. (2017) studied analytically the fully developed and the thermally developing regimes of a Herschel-Bulkley fluid by taking into account the viscous dissipation and the axial conduction with variable wall heat flux distributions which tends to infinity or zero when $x \rightarrow+\infty$. For the case where the distribution of wall heat flux tends to infinity for large values of axial coordinate $x$ (for example, exponential function), they concluded that the effect of viscous dissipation becomes negligible when the effect of axial conduction is important in the thermally developed region. They show that appreciable differences between the asymptotic values of the mixing Nusselt number $N u^{*}$ and the bulk Nusselt number $N u$ exist for values of the Peclet number less than 40. Recently, Sankad and Patil (2018) analyzed the heat transfer effect on a peristaltic flow of a Herschel-Buckley fluid, with the peristaltic wall coated with a porous lining. They noticed that the temperature profile, heat transfer coefficient and the rate of temperature decrease with increase in the Darcy number.

To the best of our knowledge, there are no results concerning the existence of a thermally developed flow for the case where the variable wall heat flux tends to a non-vanishing constant value at infinity, for forced convection to non-Newtonian yield stress fluids by taking into account viscous dissipation and axial conduction effects. So, this paper aims to complete the previous works by studying analytically the fully developed laminar forced convection in circular ducts for a HerschelBulkely fluid with viscous dissipation and axial heat conduction while considering more general axial variations of the wall heat flux, with finite non-vanishing values at infinity along the flow direction.

The fully developed values of $N u$ (usual Nusselt number employed in the literature which is defined by taking the bulk temperature as reference temperature) and $N u^{*}$ (obtained by taking the mixing temperature as reference temperature (defined in Ref. (Barletta and Zanchini 1995))) are determined. These quantities coincide when $P e \rightarrow \infty$, but are different for finite values of $P e$. Both the asymptotic Nusselt number and the asymptotic profile temperature are yields for a thermally developed region. This region has been studied in the case where the wall heat flux $q_{w}(x)$ does not vanish when $x \rightarrow+\infty$ while $\frac{1}{q_{w}(x)} \frac{d q_{w}(x)}{d x}$ tend to zero when $x \rightarrow+\infty$ to ensure the existence of the thermally developed flow region. The effects of the dimensionless radius, the plug core, the power-law exponent, the Peclet number and the Brinkman number are presented and compared with those obtained in previous works.

This paper is organized as follows: in section 2 the considered fully developed velocity profile and the energy equation are presented. In section 3, the asymptotic temperature field and the asymptotic Nusselt number are determined in the case of an axial distribution of wall heat flux given by polynomial functions, logarithmic functions, rational functions where the degree of the numerator is greater than or equal to the degree of the denominator ...etc. Section 4 is devoted to the discussion of viscous dissipation and axial heat conduction effects on convective laminar heat transfer of hydrodynamically and thermally fully developed flow for non-Newtonian fluids. The main conclusions are summarized in section 5 .

\section{ANALYSIS}

Let us consider a Herschel-Bulkley fluid of constant physical properties flowing in a circular duct of radius $r_{0}$, submitted to a variable axial wall heat flux $q_{w}(x)$. The flow is supposed to be steady, laminar, fully developed and axisymmetric.

The fully developed velocity profile for a laminar pipe flow of a Herschel-Bulkley fluid is given as follows (Nouar et al. 1994)

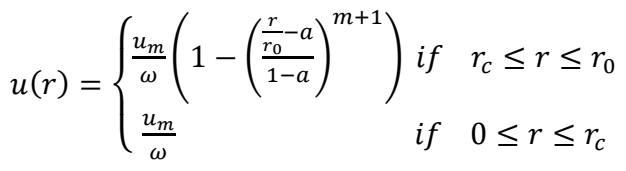

where $\omega=1-2\left(\frac{a(1-a)}{m+2}+\frac{(1-a)^{2}}{m+3}\right), m=1 / n$ is the inverse of exponent index $n$ (with $n>0$; for $n=1$ : Bingham fluid), $a=r_{c} / r_{0}$ is the dimensionless radius of the plug flow region (with $0 \leq a \leq 1$ ), $r$ the radial coordinate, $r_{c}$ the yield radius and $u_{m}$ the mean velocity value.

The energy equation and associated boundary conditions are given by (Bejan 1984)

$\rho c_{p} u \frac{\partial T}{\partial x}=\lambda \frac{\partial^{2} T}{\partial x^{2}}+\frac{\lambda}{r} \frac{\partial}{\partial r}\left[r \frac{\partial T}{\partial r}\right]+K\left|\frac{d u}{d r}\right|^{n} \frac{d u}{d r}-\tau_{c} \frac{d u}{d r}$

$\left.\frac{\partial T}{\partial r}\right|_{r=0}=0 ;\left.\frac{\partial T}{\partial r}\right|_{r=r_{0}}=\frac{q_{w}(x)}{\lambda}$

$T(r, x=0)=T_{0}(r)$

where $\rho, \lambda, K$ and $c_{p}$ are the density of fluid, thermal conductivity, the consistency index, and the specific heat at constant pressure, respectively and $x$ is the axial coordinate.

The condition that leads to an asymptotic thermally developed region in the case of the forced convection problem considered above is defined by (Bejan 1984, Barletta and Zanchini 1995) as follow

$\lim _{x \rightarrow+\infty} \frac{T_{w}(x)-T(r, x)}{T_{w}(x)-T_{b}(x)}=\lim _{x \rightarrow+\infty} \Theta\left(\frac{r}{r_{0}}, \frac{x}{2 r_{0} P e}\right)=\Theta_{\infty}\left(r / r_{0}\right)$

$\lim _{x \rightarrow+\infty} \frac{T_{w}(x)-T(r, x)}{T_{w}(x)-T_{m}(x)}=\lim _{x \rightarrow+\infty} \Theta^{*}\left(\frac{r}{r_{0}}, \frac{x}{2 r_{0} P e}\right)=\Theta_{\infty}^{*}\left(r / r_{0}\right)$

where $T_{w}(x), T_{b}(x)$ and $T_{m}(x)$ are the wall temperature, the bulk temperature and the mixing temperature, respectively, $P e=2 r_{0} u_{m} \rho c_{p} / \lambda$ is the Peclet number, $\Theta_{\infty}\left(r / r_{0}\right)$ and $\Theta_{\infty}^{*}\left(r / r_{0}\right)$ are the asymptotic dimensionless temperature which are continuous and differentiable functions of $r$. 
The bulk value of temperature field is defined as

$T_{b}(x)=\frac{2}{u_{m} r_{0}^{2}} \int_{0}^{r_{0}} T(r, x) u(r) r d r$

The mixing value of temperature field is defined as

$$
T_{m}(x)=\frac{2}{u_{m} r_{0}^{2}} \int_{0}^{r_{0}}\left(T(r, x) u(r)-\alpha \frac{\partial T}{\partial x}\right) r d r=T_{b}(x)-\frac{4}{r_{0} P e} \int_{0}^{r_{0}} \frac{\partial T}{\partial x} r d r
$$

where $\alpha$ is the thermal diffusivity of the fluid.

If condition (5) and (6) holds, the asymptotic values of the Nusselt number $N u_{\infty}$ and $N u_{\infty}^{*}$ exists (Bejan 1984, Barletta and Zanchini 1995) and are given by

$\lim _{x \rightarrow+\infty} N u=2 r_{0} \lim _{x \rightarrow+\infty} \frac{\left.\frac{\partial T}{\partial r}\right|_{r=r_{0}}}{T_{w}(x)-T_{b}(x)}=-\left.2 r_{0} \frac{d \Theta_{\infty}}{d r}\right|_{r=r_{0}}=N u_{\infty}$

$\lim _{x \rightarrow+\infty} N u^{*}=2 r_{0} \lim _{x \rightarrow+\infty} \frac{\left.\frac{\partial T}{\partial r}\right|_{r=r_{0}}}{T_{w}(x)-T_{m}(x)}=-\left.2 r_{0} \frac{d \Theta_{\infty}^{*}}{d r}\right|_{r=r_{0}}=N u_{\infty}^{*}$

Using the proof presented by Barletta (1997), it is easy to check that the boundary value problem, expressed by Eqs. (2)-(4), has a unique solution, and both the asymptotic behaviour of the temperature field and the Nusselt number are independent of the temperature distribution in the inlet section.

Introducing the dimensionless quantities (Barletta 1997)

$X=\frac{x}{2 r_{0} P e}, R=\frac{r}{r_{0}}, U(R)=\frac{u(r)}{u_{m}}, \theta=\lambda r_{0}^{n-1} \frac{T-T_{0 b}}{K u_{m}^{n+1}}$

Eqs. (2) and (3) can be rewritten in the dimensionless form

$\frac{\partial}{\partial R}\left[R \frac{\partial \theta}{\partial R}\right]=\frac{R U}{4} \frac{\partial \theta}{\partial X}-\frac{R}{4 P e^{2}} \frac{\partial^{2} \theta}{\partial X^{2}}+\frac{a}{(1-a)^{n+1}}\left(\frac{m+1}{\omega}\right)^{n} R \frac{d U}{d R}-R\left|\frac{d U}{d R}\right|^{n-1}\left(\frac{d U}{d R}\right)^{2}$

$\left.\frac{\partial \theta}{\partial R}\right|_{R=0}=\left.0 \quad \frac{\partial \theta}{\partial R}\right|_{R=1}=\frac{1}{2^{n} B r(X)}$

where $\operatorname{Br}(X)$ is a local Brinkman number defined as

$\operatorname{Br}(X)=\frac{K u_{m}^{n+1}}{\left(2 r_{0}\right)^{n} q_{w}(X)}$

Integrating Eq. (12) over the interval $0 \leq R \leq 1$ and employing Eq. (13) yields

$\frac{d \theta_{m}}{d X}=\frac{2^{3-n}}{B r(X)}+\frac{8}{(1-a)^{n+1}}\left(\frac{m+1}{\omega}\right)^{n}$

where $\theta_{m}(X)$ is the mixing value of the dimensionless temperature $\theta(R, X)$.

\section{ASYMPTOTIC BEHAVIOUR OF THE TEMPERATURE FIELD}

In this work, the asymptotic temperature field and the asymptotic Nusselt number are analyzed in the case of an axial distribution of wall heat flux which yield a thermally developed region, such as

$$
\lim _{X \rightarrow+\infty} B r(X)=B r_{\infty}
$$

and, if $B r_{\infty}=0, \quad \lim _{X \rightarrow+\infty} \frac{1}{B r(X)} \frac{d B r(X)}{d X}=0$ where $B r_{\infty}$ is the asymptotic Brinkman number, and is a real number.

Conditions (16) and (17) are checked by uniform wall heat flux distributions, and when $q_{w}(X)$ is given by polynomial functions, logarithmic functions, rational functions where the degree of the numerator is greater than or equal to the degree of the denominator among others. Under these conditions, there exists an asymptotic fully developed region for the temperature field and the solution of the Eqs. (12) and (13), for large values of X, is expressed by

$\theta(R, X)=\theta_{m}(X)+\frac{f(R)}{B r(X)}$

where $f(R)$ is a continuous and differentiable function of $R$.

Substituting Eq. (18) in Eqs. (12) and (13), and using Eqs. (15), (16) and (17), one obtains

$\frac{d}{d R}\left[R \frac{d f}{d R}\right]=\frac{1}{4}\left(2^{3-n}+\frac{8}{(1-a)^{n+1}}\left(\frac{m+1}{\omega}\right)^{n} B r_{\infty}\right) R U+$

$B r_{\infty}\left[\frac{a}{(1-a)^{n+1}}\left(\frac{m+1}{\omega}\right)^{n} R \frac{d U}{d R}-R\left|\frac{d U}{d R}\right|^{n-1}\left(\frac{d U}{d R}\right)^{2}\right]$

$\left.\frac{d f}{d R}\right|_{R=0}=0,\left.\frac{d f}{d R}\right|_{R=1}=\frac{1}{2^{n}}$

The integration of Eq. (19) taking into account the continuity of $f(R)$ at $R=a$ and the vanishing bulk value of $f(R)$ gives the expression of $f(R)$ (see Appendix), and using Eqs. (6), (11), and (18), gives the following asymptotic mixing temperature field

$\Theta_{\infty}^{*}(R)=\frac{f(1)-f(R)}{f(1)}$

Where $f(1)$ is the expression of $f(R)$ at the wall $R=1$ obtained analytically and given in Appendix.

By using Eqs. (5), (8), (11), (15) and (18), the asymptotic bulk temperature field is given as

$\Theta_{\infty}(R)=\frac{f(1)-f(R)}{f(1)-\frac{1}{P e^{2}}\left[2^{3-n}+\frac{8}{(1-a)^{n+1}}\left(\frac{m+1}{\omega}\right)^{n} B r_{\infty}\right]}$

Taking into account Eqs. (9), (10), (20), (21) and (22), the asymptotic value of the mixing and bulk Nusselt number yield

$$
\begin{aligned}
& N u_{\infty}^{*}=-\left.2 \frac{d \Theta_{\infty}^{*}}{d R}\right|_{R=1}=\frac{2^{1-n}}{f(1)} \\
& N u_{\infty}=-\left.2 \frac{d \Theta_{\infty}}{d R}\right|_{R=1}=\frac{2^{1-n}}{f(1)-\frac{1}{P e^{2}}\left[2^{3-n}+\frac{8}{(1-a)^{n+1}}\left(\frac{m+1}{\omega}\right)^{n} B r_{\infty}\right]}
\end{aligned}
$$

Equation (24) shows that for large value of $P e$ i.e for $P e \rightarrow \infty$, the asymptotic value of the mixing and bulk Nusselt numbers are equal $N u_{\infty}=N u_{\infty}^{*}$, and therefore that the effect of axial conduction is negligible. We also notice that for a given Peclet number, there is a value of the Brinkman number which produces a singularity in both the asymptotic $N u_{\infty}$ and $\Theta_{\infty}(R)$. This means that the bulk fluid motion may increase heat transfer.

\section{RESULTS AND DISCUSSION}

This section is devoted to the discussion of the results of the asymptotic behaviour of the temperature field and the Nusselt number. The asymptotic bulk and mixing Nusselt numbers and the asymptotic bulk and mixing temperature distributions of the Herschel-Bulkley fluids 
flowing in circular ducts are calculated by considering the effects of viscous dissipation and fluid axial heat conduction.

Equation (23) shows that $N u_{\infty}^{*}$ is independent of the Peclet number (see Table 1). Equation (24) shows that the asymptotic value of the bulk Nusselt number depends only on the core radius $a$, the power-law index $n$, the Peclet number $P e$, and the asymptotic value $B r_{\infty}$ of the Brinkman number. The values of $N u$ and $N u^{*}$ as function of $B r_{\infty}, a, P e$ and $n$ are reported in Table 1.

Concerning the asymptotic bulk Nusselt number $N u_{\infty}$, when the axial heat conduction is taken into account (for example : $P e=10$ ), $N u_{\infty}$ increases when the core radius increases and viscous dissipation is negligible $\left(B r_{\infty}=0\right)$, but it decreases in the presence of viscous dissipation (see Table 1). For a given core radius value $a$, when the viscous dissipation and axial heat conduction coexist, the asymptotic Nusselt number increases when $n$ decreases. Furthermore, let us emphasize that for $P e=10, B r_{\infty}=1$ and $n=1 / 3,1$, the values of $N u_{\infty}$ are positive while they are negative for $n=3$ (see Table 1), this sign reversal is linked to singularities for both the asymptotic Nusselt number and the temperature field.

Equation (23) is valid for a broad range of distributions of nonuniform wall heat flux which satisfy Eqs. (16) and (17), both for Newtonian, power law, Bingham and Herschel-Bulkley fluids. If the distribution of heat flux at the wall is such that $B r_{\infty}=0$ and $a=0, \mathrm{Eq}$. (23) reduces to

$N u_{\infty}^{*}=\frac{8(3 n+1)(5 n+1)}{31 n^{2}+12 n+1}$

Equation (25) coincides with the result found by Grigull (1956) for a power-law fluid in a circular tube with negligible viscous dissipation and uniform wall flux. In particular, in the Newtonian fluid case $(n=1$, $a=0)$ with negligible viscous dissipation $\left(B r_{\infty}=0\right)$, we obtain the asymptotic value $N u_{\infty}^{*}=\frac{48}{11}=4.3636$, which coincides with that found in the literature (Zanchini 1997). Moreover, equation 25 recalls the known result of the Nusselt number as a decreasing function of the index of a power law fluid.

Table 2 shows that the asymptotic values of $N u_{\infty}^{*}$ coincide with those found by Barletta (1997) in the case of power-law fluids $(a=0)$ and with those found in the case of Bingham fluids $(n=1)$ (Khatyr et al., 2003) when the axial heat conduction is negligible $(P e \rightarrow \infty)$ and for boundary conditions on the wall heat flux identical to those given by Eqs. (16) and (17). We notice that, in the case where the viscous dissipation is negligible $\left(B r_{\infty}=0\right)$ and $(n=1)$ the mixing Nusselt number $N u_{\infty}^{*}$ increases when the core radius $a$ increases. In the case where the viscous dissipation is not negligible $\left(B r_{\infty}=-1,1\right)$ the situation is opposite and the Nusselt number $N u_{\infty}^{*}$ decreases when the core radius $a$ increases. This observation remains valid for the cases $n=1 / 3$ and $n=3$. We thus note that for the considered boundary conditions, viscous dissipation disadvantages heat transfer when the dimension of the core radius increases.

Figures 1a-b illustrates the asymptotic behaviour of the dimensionless bulk temperature field for various values of the Peclet number $P e=1,10,100,1000$, core radius $a=0,0.4$, power-law exponent $n=1 / 3,3$ and for $B r_{\infty}=-1$. For $n=1 / 3$, we note that the gradient of $\Theta_{\infty}(R)$ at the wall changes sign when the Peclet number increases, and therefore this reflects a change in sign of the asymptotic values of $N u_{\infty}$.

Figures 2a-b illustrates the asymptotic behaviour of the dimensionless bulk temperature field for various values of $B r_{\infty}=-1,0,1$, core radius $a=0,0.4$, power-law exponent $n=1 / 3,3$ and for the Peclet number $P e=10$.

This figure shows that $\Theta_{\infty}(R)$ varies significantly with Peclet number $P e$, power-law index $n$, core radius $a$ and asymptotic Brinkman number $B r_{\infty}$. It can be seen from these figures that the effect of the axial heat conduction becomes negligible for large values of Peclet number (see Figs. 1a-b). For low Peclet number, the axial heat conduction is more significant.

Indeed, Eqs. (23) and (24) shows that for given values of $n, a$ and $P e$, there is a value of the Brinkman number, which produces a singularity in the asymptotic value of $N u^{*}$ and $N u$. This value is given by:

$B r_{\infty}^{(s)}=\frac{A}{B}$

where

$$
\begin{aligned}
& B=\frac{1}{(1-a)^{n+1}}\left(\frac{m+1}{\omega}\right)^{n}\left[-\frac{8}{P e^{2}}+\frac{\omega^{2}}{2}-\frac{1}{4}+\frac{(1-a)^{2}}{(m+2)(m+3)}\left(( m + 1 ) \left(\frac{a^{2}}{m+2}+\right.\right.\right. \\
& \left.\left.\left.\frac{2 a(1-a)}{m+4}+\frac{(m+2)(1-a)^{2}}{(m+3)(m+5)}\right)+\frac{3 a+m}{1-a}+\frac{6(1-a)(m+4+a)}{(m+4)(m+5)}\right)\right]
\end{aligned}
$$

and

$A=-2^{2-n}\left\{-\frac{2}{P e^{2}}+\frac{\omega}{8}-\frac{1}{16}+\frac{(1-a)^{2}}{(m+2)(m+3)}\left(-\frac{\omega}{2}+\right.\right.$

$\frac{(m+1)}{2}\left(\frac{2 a}{(m+4)(2 m+5)}+\frac{1-a}{(m+3)(m+5)}\right)+\frac{3 a+m}{4(1-a)}+\frac{3(1-a)(m+4+a)}{2(m+4)(m+5)}-$ $\left.\left.\frac{1}{(1-a)^{m+3}} C(a, n)\right)\right\}$

where

\section{$\underline{\text { If } \boldsymbol{m} \in \mathbb{N}^{*}:}$}

$C(a, n)=(-1)^{m+3} a^{m+3}\left[\frac{a^{2}-1}{4}+\frac{(1-a)^{2}}{(m+2)(m+3)}\left(1+\frac{(-1)^{m+3} \ln (a)}{(1-a)^{m+3}}\right)\right]+$ $\sum_{k=0}^{m+2} \frac{(m+3) !(-1)^{k} a^{k}}{k !(m+3-k) !(m+3-k)}\left[-\frac{\omega}{2}+\frac{2+(m+3-k) a^{m+5-k}}{2(m+5-k)}-\right.$ $\left.\frac{1}{(1-a)^{m+1}}\left(\frac{(-1)^{m+3} a^{m+3}}{(m+2)(m+3)}+\sum_{p=0}^{m+1} \frac{(m+1) !(-1)^{p} a^{p}}{p !(m+1-p) !} \frac{1-a^{2 m+6-k-p}}{2 m+6-k-p}\right)\right]$

\section{$\underline{\text { If } m \in \mathbb{Q}^{*}}:$}

$C(a, n)=\sum_{k=0}^{\infty} \frac{P(m+3-k)(-1)^{k} a^{k}}{k !(m+3-k)^{2}}\left[-\frac{\omega}{2}+\frac{2+(m+3-k) a^{m+5-k}}{2(m+5-k)}-\right.$
$\left.\frac{1}{(1-a)^{m+1}} \sum_{p=0}^{\infty} \frac{P(m+1-p)(-1)^{p} a^{p}}{p !(m+1-p)} \frac{1-a^{2 m+6-k-p}}{2 m+6-k-p}\right]$

If $a=0$ (i.e., in the case power-law fluid) and $P e \rightarrow \infty$ (negligible axial heat conduction), then Eq. (26) reduce to (Barletta 1997) :

$B r_{\infty}^{(s)}=-2^{-n}\left(\frac{n}{3 n+1}\right)^{n} \frac{31 n^{2}+12 n+1}{(3 n+1)(5 n+1)}$

Figure 3 represents the evolution of $B r_{\infty}^{(s)}$ versus $n$ for various values of $P e$ and $a$. This figure show that the values of $B r_{\infty}^{(s)}$ change sign in the vicinity of the value $P e=5$.

Figures 4 represent the evolution of the asymptotic behaviour of the Nusselt number versus $B r_{\infty}$ for various values of $a$ and $P e$. However, if $B r_{\infty}>B r_{\infty}^{(s)}$ the value of $N u_{\infty}$ is decreasing function of $a$, whereas for $B r_{\infty}<B r_{\infty}^{(s)}$ the asymptotic value of $N u_{\infty}$ is an increasing function of $a$. These figures show that the asymptotic Nusselt number $N u_{\infty}$ is dependent of Brinkman number $B r_{\infty}$ in the case of wall heat flux conditions satisfying Eqs. (16) and (17). This result is the opposite to the case of an imposed uniform wall temperature for which the asymptotic Nusselt number $N u_{\infty}$ is independent of Brinkman number when the axial heat conduction is taken into account as noted by Jambal et al. (2005) for power-law fluids. 
Table 1 Values of $N u$ and $N u^{*}$ (in brackets) as a function of $B r_{\infty}$ and $P e$, for various values of $a$ and $n$.

\begin{tabular}{|c|c|c|c|c|c|}
\hline \multicolumn{3}{|c|}{$B r_{\infty}$} & -1 & $\mathbf{0}$ & 1 \\
\hline \multirow{9}{*}{$a=0$} & \multirow{3}{*}{$P e=10$} & $n=1 / 3$ & $\begin{array}{c}-27.2593 \\
(-11.3299)\end{array}$ & $\begin{array}{c}6.3325 \\
(5.0526)\end{array}$ & $\begin{array}{c}2.8367 \\
(2.0657)\end{array}$ \\
\hline & & $n=1$ & $\begin{array}{c}-2.0374 \\
(-1.2973) \\
\end{array}$ & $\begin{array}{c}5.2863 \\
(4.3636) \\
\end{array}$ & $\begin{array}{c}1.1505 \\
(0.8136) \\
\end{array}$ \\
\hline & & $n=3$ & $\begin{array}{c}0.0035 \\
(-0.0272) \\
\end{array}$ & $\begin{array}{c}4.8338 \\
(4.0506) \\
\end{array}$ & $\begin{array}{c}-0.0035 \\
(0.0268) \\
\end{array}$ \\
\hline & \multirow{3}{*}{$P e=100$} & $n=1 / 3$ & $\begin{array}{c}-11.3965 \\
(-11.3299) \\
\end{array}$ & $\begin{array}{c}5.0629 \\
(5.0526) \\
\end{array}$ & $\begin{array}{c}2.0713 \\
(2.0657) \\
\end{array}$ \\
\hline & & $n=1$ & $\begin{array}{c}-1.3020 \\
(-1.2973) \\
\end{array}$ & $\begin{array}{c}4.3713 \\
(4.3636) \\
\end{array}$ & $\begin{array}{c}0.8159 \\
(0.8135) \\
\end{array}$ \\
\hline & & $n=3$ & $\begin{array}{c}-0.0298 \\
(-0.0272)\end{array}$ & $\begin{array}{c}4.0572 \\
(4.0506)\end{array}$ & $\begin{array}{c}0.0293 \\
(0.0268)\end{array}$ \\
\hline & \multirow{3}{*}{$P e=1000$} & $n=1 / 3$ & $\begin{array}{c}-11.3306 \\
(-11.3299) \\
\end{array}$ & $\begin{array}{c}5.0527 \\
(5.0526) \\
\end{array}$ & $\begin{array}{c}2.0658 \\
(2.0657) \\
\end{array}$ \\
\hline & & $n=1$ & $\begin{array}{c}-1.2973 \\
(-1.2973) \\
\end{array}$ & $\begin{array}{c}4.3637 \\
(4.3636) \\
\end{array}$ & $\begin{array}{c}0.8136 \\
(0.8136) \\
\end{array}$ \\
\hline & & $n=3$ & $\begin{array}{c}-0.0272 \\
(-0.0272)\end{array}$ & $\begin{array}{c}4.0507 \\
(4.0506) \\
\end{array}$ & $\begin{array}{c}0.0268 \\
(0.0268) \\
\end{array}$ \\
\hline \multirow{9}{*}{$a=0.4$} & \multirow{3}{*}{$P e=10$} & $n=1 / 3$ & $\begin{array}{c}-4.3721 \\
(-2.7765) \\
\end{array}$ & $\begin{array}{c}7.3752 \\
(5.6951) \\
\end{array}$ & $\begin{array}{c}2.0004 \\
(1.4058) \\
\end{array}$ \\
\hline & & $n=1$ & $\begin{array}{c}-0.7896 \\
(-0.5264) \\
\end{array}$ & $\begin{array}{c}6.0764 \\
(4.8883) \\
\end{array}$ & $\begin{array}{c}0.6267 \\
(0.4331)\end{array}$ \\
\hline & & $n=3$ & $\begin{array}{c}0.0014 \\
(-0.0106) \\
\end{array}$ & $\begin{array}{c}5.4174 \\
(4.4525) \\
\end{array}$ & $\begin{array}{c}-0.0014 \\
(0.0105) \\
\end{array}$ \\
\hline & \multirow{3}{*}{$P e=100$} & $n=1 / 3$ & $\begin{array}{c}-2.7867 \\
(-2.7765) \\
\end{array}$ & $\begin{array}{c}5.7081 \\
(5.6951) \\
\end{array}$ & $\begin{array}{c}1.4100 \\
(1.4058) \\
\end{array}$ \\
\hline & & $n=1$ & $\begin{array}{c}-0.5281 \\
(-0.5264)\end{array}$ & $\begin{array}{c}4.8979 \\
(4.8883)\end{array}$ & $\begin{array}{c}0.4344 \\
(0.4331)\end{array}$ \\
\hline & & $n=3$ & $\begin{array}{c}-0.0116 \\
(-0.0106) \\
\end{array}$ & $\begin{array}{c}4.4605 \\
(4.4525) \\
\end{array}$ & $\begin{array}{c}0.0115 \\
(0.0105) \\
\end{array}$ \\
\hline & \multirow{3}{*}{$P e=1000$} & $n=1 / 3$ & $\begin{array}{c}-2.7766 \\
(-2.7765)\end{array}$ & $\begin{array}{c}5.6952 \\
(5.6951)\end{array}$ & $\begin{array}{c}1.4058 \\
(1.4058)\end{array}$ \\
\hline & & $n=1$ & $\begin{array}{c}-0.5264 \\
(-0.5264) \\
\end{array}$ & $\begin{array}{c}4.8884 \\
(4.8883) \\
\end{array}$ & $\begin{array}{c}0.4331 \\
(0.4331) \\
\end{array}$ \\
\hline & & $n=3$ & $\begin{array}{c}-0.0106 \\
(-0.0106) \\
\end{array}$ & $\begin{array}{c}4.4526 \\
(4.4525) \\
\end{array}$ & $\begin{array}{c}0.0106 \\
(0.0105) \\
\end{array}$ \\
\hline \multirow{9}{*}{$a=0.8$} & \multirow{3}{*}{$P e=10$} & $n=1 / 3$ & $\begin{array}{c}-0.7197 \\
(-0.4873)\end{array}$ & $\begin{array}{c}9.6508 \\
(6.9629)\end{array}$ & $\begin{array}{c}0.6263 \\
(0.4275)\end{array}$ \\
\hline & & $n=1$ & $\begin{array}{c}-0.1040 \\
(-0.0706) \\
\end{array}$ & $\begin{array}{c}8.5869 \\
(6.3915) \\
\end{array}$ & $\begin{array}{c}0.1015 \\
(0.0691) \\
\end{array}$ \\
\hline & & $n=3$ & $\begin{array}{c}0.00005 \\
(-0.0004) \\
\end{array}$ & $\begin{array}{c}3.2437 \\
(2.8712) \\
\end{array}$ & $\begin{array}{r}-0.00005 \\
(0.0004) \\
\end{array}$ \\
\hline & \multirow{3}{*}{$P e=100$} & $n=1 / 3$ & $\begin{array}{c}-0.4889 \\
(-0.4873) \\
\end{array}$ & $\begin{array}{c}6.9824 \\
(6.9629) \\
\end{array}$ & $\begin{array}{c}0.4289 \\
(0.4275) \\
\end{array}$ \\
\hline & & $n=1$ & $\begin{array}{c}-0.0709 \\
(-0.0706) \\
\end{array}$ & $\begin{array}{c}6.4079 \\
(6.3915) \\
\end{array}$ & $\begin{array}{c}0.0693 \\
(0.0691) \\
\end{array}$ \\
\hline & & $n=3$ & $\begin{array}{c}-0.0004 \\
(-0.0004) \\
\end{array}$ & $\begin{array}{c}2.8745 \\
(2.8712) \\
\end{array}$ & $\begin{array}{c}0.0004 \\
(0.0004) \\
\end{array}$ \\
\hline & \multirow{3}{*}{$P e=1000$} & $n=1 / 3$ & $\begin{array}{c}-0.4874 \\
(-0.4873) \\
\end{array}$ & $\begin{array}{c}6.9631 \\
(6.9629) \\
\end{array}$ & $\begin{array}{c}0.4275 \\
(0.4275) \\
\end{array}$ \\
\hline & & $n=1$ & $\begin{array}{c}-0.0706 \\
(-0.0706)\end{array}$ & $\begin{array}{c}6.3917 \\
(6.3915)\end{array}$ & $\begin{array}{c}0.0691 \\
(0.0691)\end{array}$ \\
\hline & & $n=3$ & $\begin{array}{c}-0.0004 \\
(-0.0004)\end{array}$ & $\begin{array}{c}2.8712 \\
(2.8712)\end{array}$ & $\begin{array}{c}0.0004 \\
(0.0004)\end{array}$ \\
\hline
\end{tabular}


Table 2 Values of $N u_{\infty}^{*}$ as function $B r_{\infty}$, for various values of $a$, $n$, and $P e \rightarrow \infty$.

\begin{tabular}{|c|c|c|c|c|c|c|c|c|c|}
\hline \multirow[b]{2}{*}{$\boldsymbol{a}$} & \multicolumn{3}{|c|}{$n=1 / 3$} & \multicolumn{3}{|c|}{$\boldsymbol{n}=\mathbf{1}$ (Khatyr et al. 2003) } & \multicolumn{3}{|c|}{$n=3$} \\
\hline & $B r_{\infty}=-1$ & $B r_{\infty}=\mathbf{0}$ & $B r_{\infty}=1$ & $B r_{\infty}=-1$ & $B r_{\infty}=0$ & $B r_{\infty}=1$ & $B r_{\infty}=-1$ & $B r_{\infty}=0$ & $B r_{\infty}=1$ \\
\hline $\mathbf{0}$ & -11.3299 & 5.0526 & 2.0657 & -1.2973 & 4.3636 & 0.8136 & -0.0272 & 4.0526 & 0.0268 \\
\hline 0.2 & -5.3409 & 5.3223 & 1.7762 & -0.8749 & 4.5528 & 0.6320 & -0.0191 & 4.1584 & 0.0189 \\
\hline 0.4 & -2.7765 & 5.6951 & 1.4058 & -0.5264 & 4.8883 & 0.4331 & -0.0106 & 4.4367 & 0.0105 \\
\hline 0.6 & -1.3618 & 6.2133 & 0.9468 & -0.2545 & 5.4543 & 0.2328 & -0.0037 & 5.0005 & 0.0037 \\
\hline 0.8 & -0.4864 & 7.1702 & 0.4283 & -0.0706 & 6.3916 & 0.0691 & -0.0004 & 6.0064 & 0,0004 \\
\hline $\begin{array}{c}\text { Barletta (1997) } \\
\boldsymbol{a}=\mathbf{0}\end{array}$ & -11.3299 & 5.0526 & 2.0657 & -1.2973 & 4.3636 & 0.8136 & -0.0272 & 4.0526 & 0.0268 \\
\hline
\end{tabular}
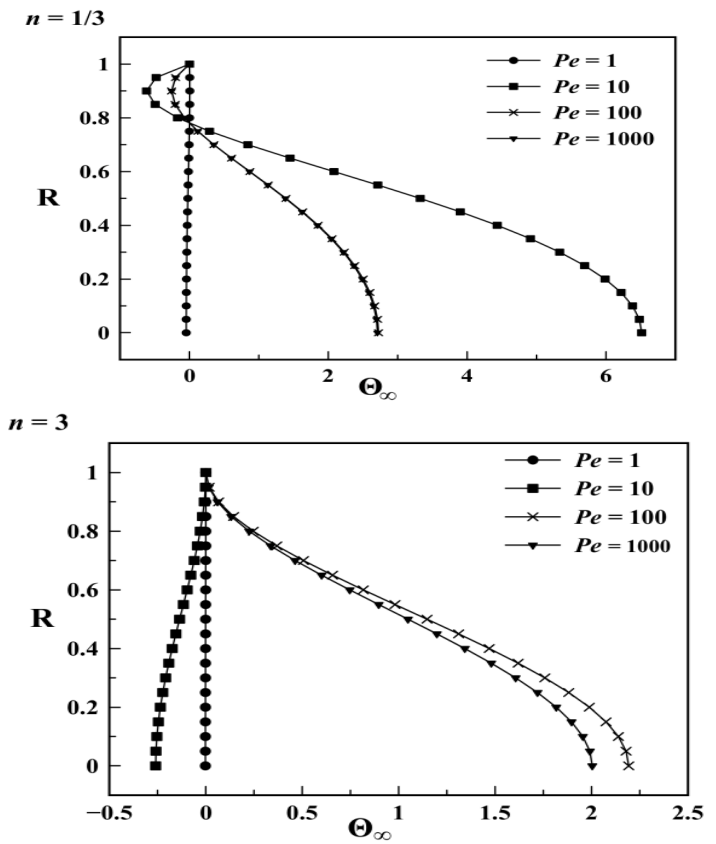

(a) : $a=0$
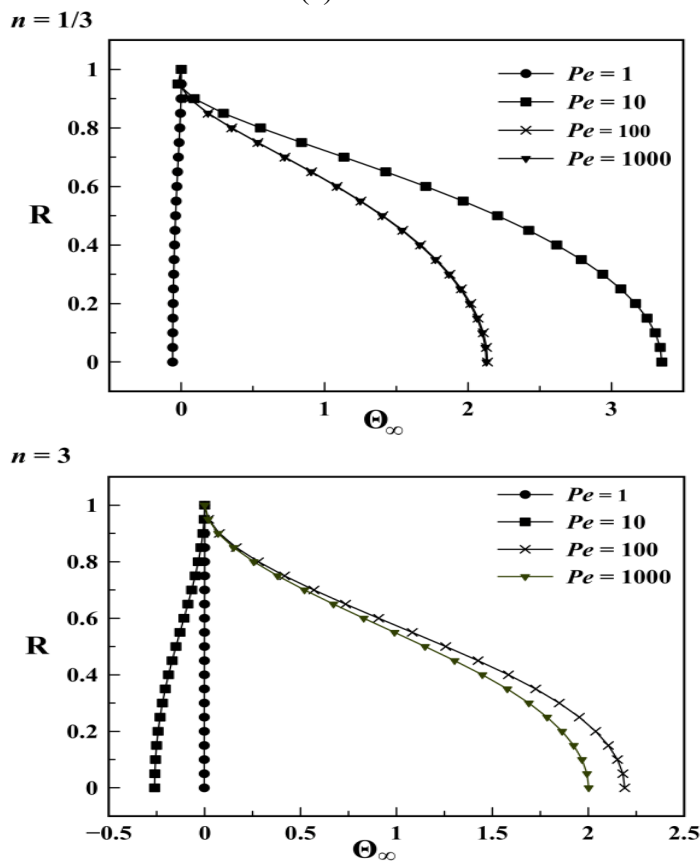

(b) : $a=0.4$

Fig. 1 Evolution of $\Theta_{\infty}(R)$ for various values of $P e, n, a$ and for $\mathrm{Br}_{\infty}=-1$
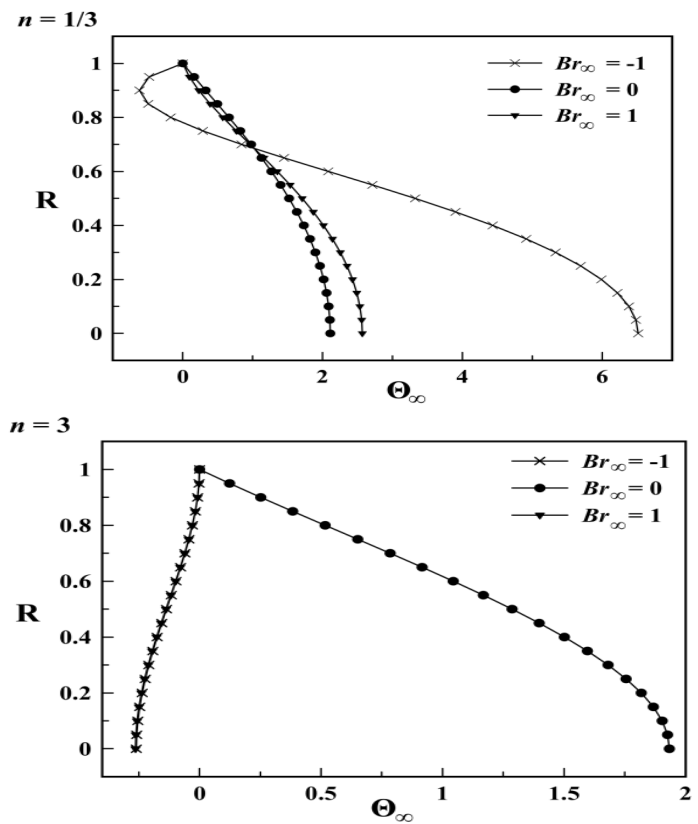

(a) : $a=0$
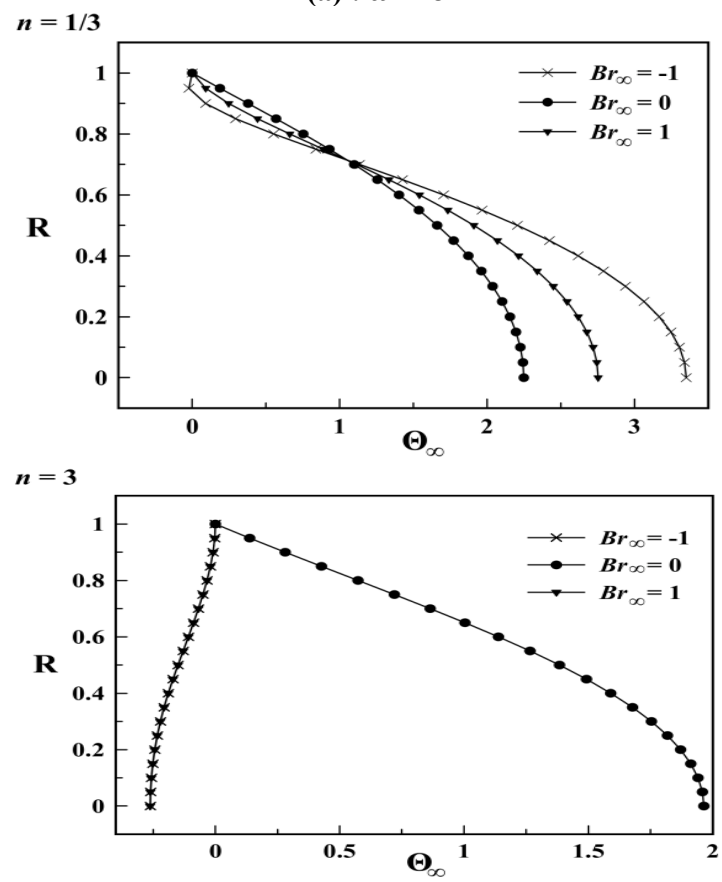

(b) : $a=0.4$

Fig. 2 Evolution of $\Theta_{\infty}(R)$ for various values of $\mathrm{Br}_{\infty}, n, a$ and for $P e=10$ 


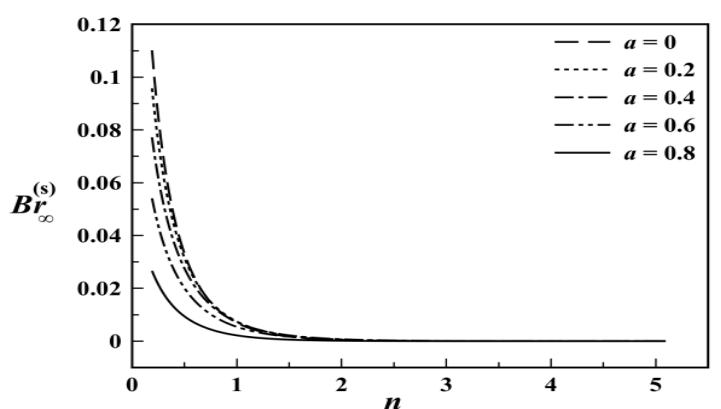

(a) $P e=4$

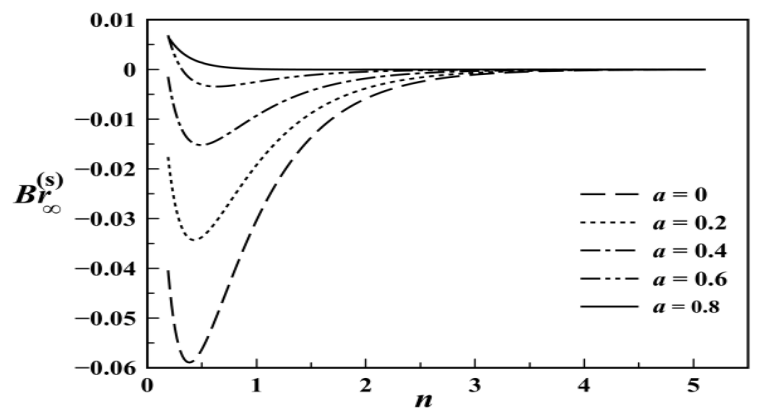

(b) $P e=5$

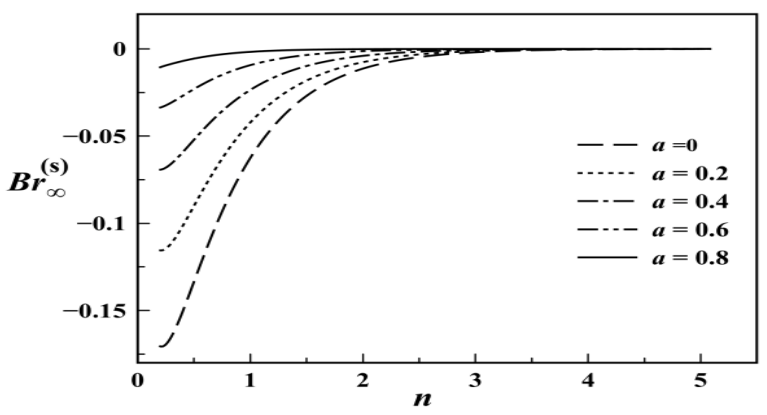

(c) $P e=6$

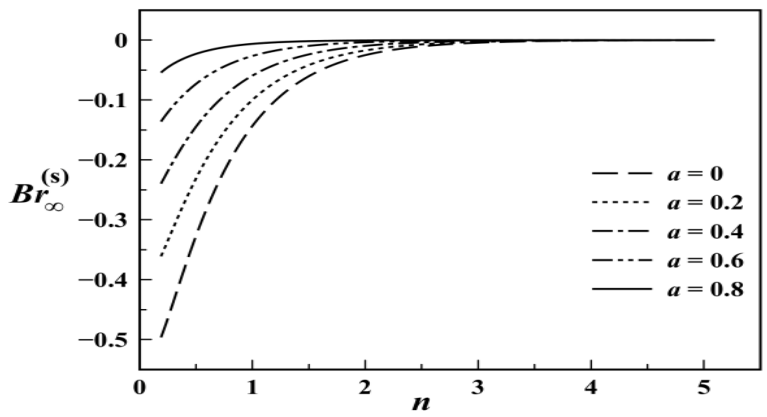

(d) $P e=10$

Fig. 3 Variation of $B r_{\infty}^{(s)}$ versus the core radius $a$ for various values of Pe
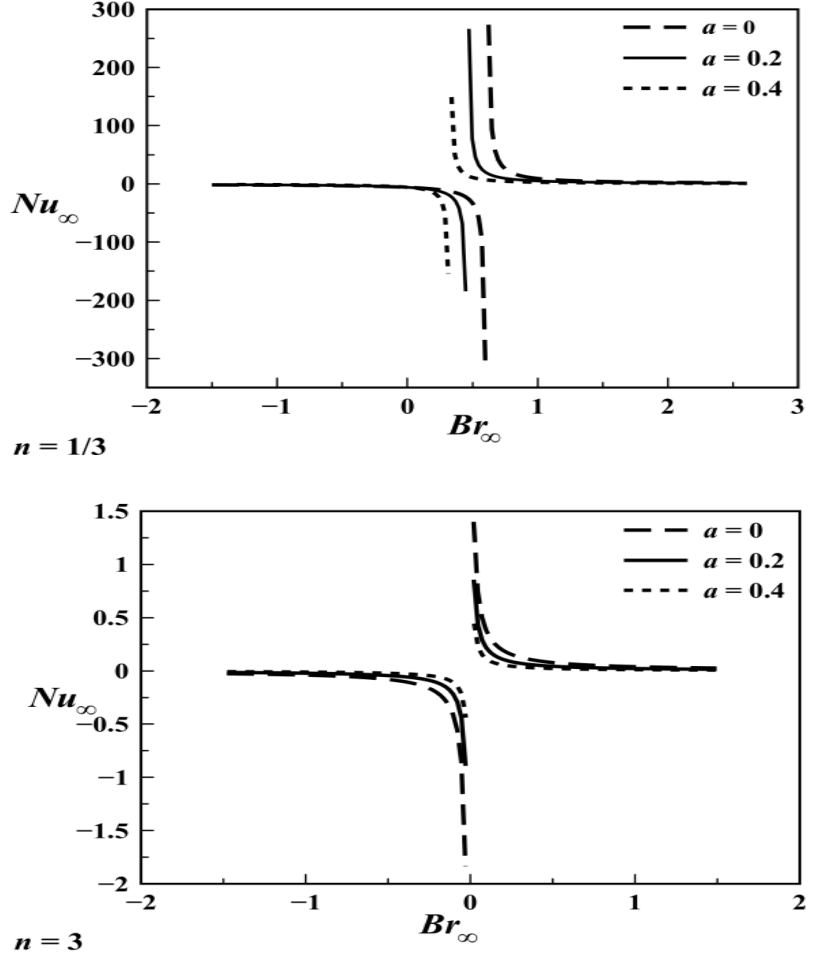

(a) : $P e=10$
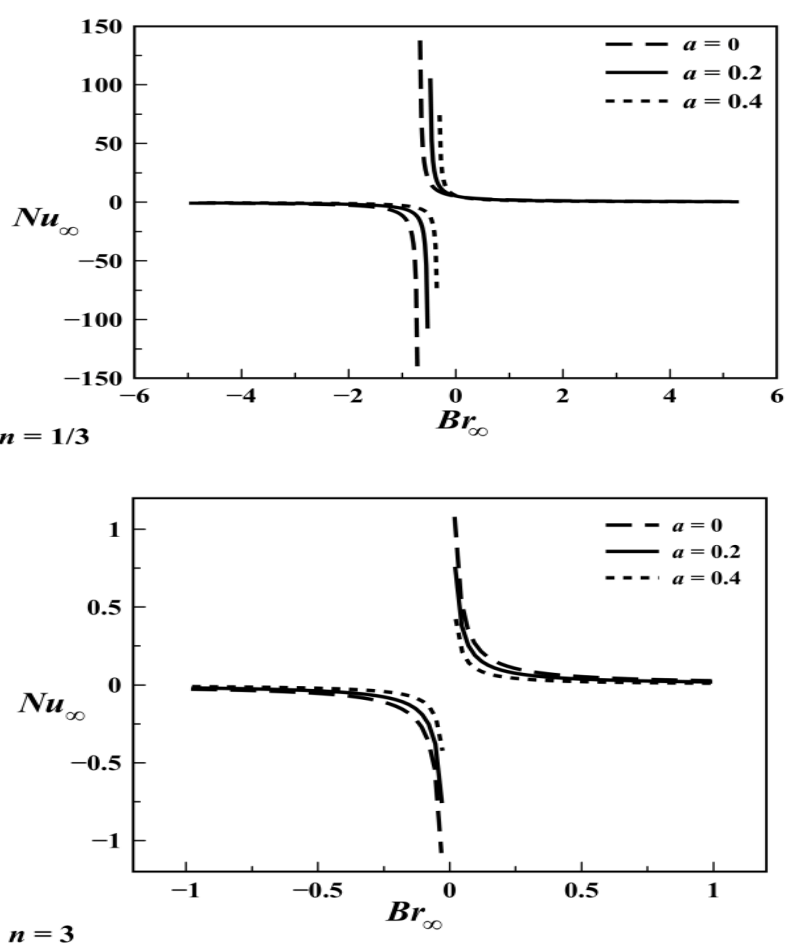

(b) : Pe $\rightarrow \infty$

Fig. 4 Variation of $N u_{\infty}$ versus $B r_{\infty}$ for different values of $a$ and $P e$ 
A comparison between $N u_{\infty}^{*}$ and $N u_{\infty}$ is illustrated in Figs. 5a-b in the cases where $a=0$ and $a=0.4, n=1 / 3$ and $B r_{\infty}=1$. We note that appreciable differences between $N u^{*}$ and $N u$ exist only for $P e \leq 20$ and that the $N u_{\infty}$ changes sign in the vicinity of $P e=5$. We can conclude that for low Peclet number, the effect of axial heat conduction and of viscous dissipation are significant.

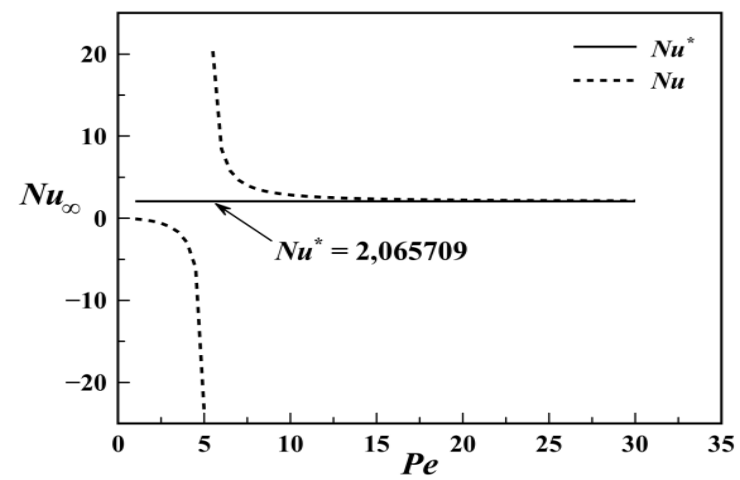

(a) $a=0$

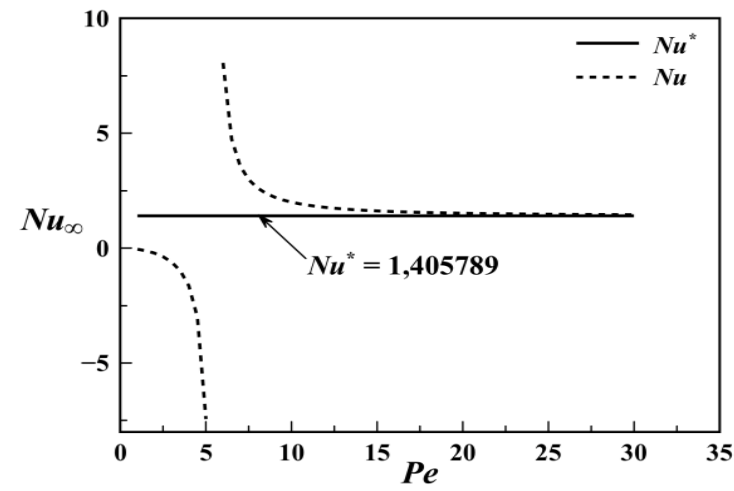

(b) $a=0.4$

Fig. 5 Variation of $N u_{\infty}$ and $N u_{\infty}^{*}$ versus $P e$ for $B r_{\infty}=1, n=1 / 3$ and for : (a) $a=0$, (b) $a=0.4$

\section{CONCLUSION}

Forced laminar convection in a circular tube with a fully developed velocity profile and a prescribed axial distribution of wall heat flux has been considered. Both the effect of axial conduction in the fluid and the viscous dissipation has been taken into account.

It has been supposed that when $x \rightarrow+\infty$, the wall heat flux distribution $q_{w}(x)$ is finite and non-vanishing, while $\frac{1}{q_{w}(x)} \frac{d q_{w}(x)}{d x}$ tends to zero. The fully developed values of both $N u_{\infty}$ and $N u_{\infty}^{*}$ have been evaluated analytically as a function of the asymptotic Brinkman number $B r_{\infty}$, the power-law index $n$, the core radius $a$ and the Peclet number $P e$.

The obtained analytical solutions have been favorably compared to the previous studies' solutions. It has been shown that the effect of viscous dissipation and axial heat conduction are significant in the thermally developed region. In addition, the value of $B r_{\infty}$ which produces a singularity as function of $a, n$ and $P e$ (Eq. 26) was presented.

\section{NOMENCLATURE}

a ratio of yield shear stress to wall shear stress

$\operatorname{Br}(X)$ local Brinkman number

$c_{p} \quad$ specific heat at constant pressure $\left(\mathrm{J} \cdot \mathrm{kg}^{-1} \cdot \mathrm{K}^{-1}\right)$

$K \quad$ consistency index (Pa.s)

$n$ power-law exponent

$N u$ bulk Nusselt number, $2 r_{0} q_{w} /\left[\lambda\left(T_{w}-T_{b}\right)\right]$
$N u^{*}$ mixing Nusselt number, $2 r_{0} q_{w} /\left[\lambda\left(T_{w}-T_{m}\right)\right]$

$m$ inverse of exponent index $n$

$P e \quad$ Peclet number, $2 r_{0} u_{m} \rho c_{p} / \lambda$

$q_{w} \quad$ wall heat flux $\left(\mathrm{W} \cdot \mathrm{m}^{-1}\right)$

$r \quad$ radial coordinate $(\mathrm{m})$

$r_{0} \quad$ radius of the tube $(\mathrm{m})$

$r_{c} \quad$ the yield radius (m)

$R \quad$ dimensionless radial coordinate

$T$ temperature $(\mathrm{K})$

$T_{0} \quad$ inlet temperature distribution (K)

$u \quad$ velocity component in the axial direction $\left(\mathrm{m} . \mathrm{s}^{-1}\right)$

$u_{m}$ mean axial velocity $\left(\mathrm{m} . \mathrm{s}^{-1}\right)$

$U$ dimensionless axial velocity

$x \quad$ axial coordinate $(\mathrm{m})$

$X$ dimensionless axial coordinate

Greeks Symbols

$\alpha \quad$ thermal diffusivity of fluid $\left(\mathrm{m}^{2} \cdot \mathrm{s}^{-1}\right)$

$\lambda \quad$ thermal conductivity of fluid $\left(\mathrm{W} \cdot \mathrm{m}^{-1} \cdot \mathrm{K}^{-1}\right)$

$\rho \quad$ fluid density $\left(\mathrm{kg} . \mathrm{m}^{-3}\right)$

$\theta$ dimensionless temperature

$\Theta \quad$ dimensionless bulk temperature

$\Theta^{*} \quad$ dimensionless mixing temperature

Subscripts

$b \quad$ bulk quantity

$m$ mixing quantity

$w \quad$ wall condition

$\infty \quad$ quantity evaluated for $X \rightarrow+\infty$

\section{REFERENCES}

Aydin, O., 2005, "Effects of viscous dissipation on the heat transfer in forced pipe flow. Part 1: both hydrodynamically and thermally fully developed flow," Energ. Convers. Manage., 46, 757-769. https://doi.org/10.1016/j.enconman.2004.05.004

Aydin, O., 2005, "Effects of viscous dissipation on the heat transfer in forced pipe flow. Part 2: Thermally developing flow," Energ. Convers. Manage., 46, 3091-3102.

https://doi.org/10.1016/j.enconman.2005.03.011

Aydin, O., and Avci, M., 2006, "Viscous-dissipation effects on the heat transfer in Poiseuille flow," Applied Energy, 83, 495-512. https://doi.org/10.1016/j.apenergy.2005.03.003

Barletta, A., 1997, "Fully developed laminar forced convection in circular ducts for power-law fluids with viscous dissipation," Int. J. Heat Mass Transfer, 40, 15-26. https://doi.org/10.1016/S0017-9310(96)00094-4

Barletta, A., and Rossi Di Schio, E., 2000, "Periodic forced convection with axial heat conduction in a circular duct," Int. J. Heat Mass Transfer, 43, 2949-2960.

https://doi.org/10.1016/S0017-9310(99)00360-9

Barletta, A., and Zanchini, E., 1996, "The existence of an asymptotic thermally developed region for laminar forced convection in a circular duct," Int. J. Heat Mass Transfer, 39(13), 2735-2744.

https://doi.org/10.1016/0017-9310(95)00358-4

Barletta, A., and Zanchini, E., 1996, "Thermal entrance region for laminar forced convection in a circular tube with a power-law wall heat flux," Int. J. Heat Mass Transfer, 39, 1265-1272. https://doi.org/10.1016/0017-9310(95)00200-6

Barletta, A., and Zanchini, E., 1995, "Laminar forced convection with sinusoidal wall heat flux distribution: axially periodic regime," Heat Mass Transfer, 31, 41-48. 


\section{https://doi.org/10.1007/BF02537420}

Barletta, A., and Zanchini, E., 1999, "Effects of viscous dissipation on laminar forced convection with axially periodic wall heat flux," Heat Mass Transfer, 35, 9-16.

https://doi.org/10.1007/s002310050292

Barletta, A., and Zanchini, E., 1995, "On the laminar forced convection with axial conduction in a circular tube with exponential wall heat flux," Heat and Mass Transfer, 30, 238-290.

https://doi.org/10.1007/BF01463917

Bejan, A., 1984, “Convection heat transfer," (1 ${ }^{\text {st Edn }), ~ N e w ~ Y o r k: ~ W i l e y . ~}$

Dang, Vi-D., 1984, "Forced convection heat transfer of power law fluid at low Peclet number flow," Chem. Eng. Res. Des., 62, 365-372.

Ditchfield,C., Tadini, C.C., Singh, R.K., and Toledo, R.T., 2006, "Velocity and temperature profiles, heat transfer coefficients and residence time distribution of a temperature dependent HerschelBulkley fluid in a tubular heat exchanger," J. Food Eng., 76, 632-638. https://doi.org/10.1016/j.jfoodeng.2005.06.015

Gräber, H., 1968, "Transfert de chaleur dans des tubes lisses, entre des plaques planes parallèles, le long d'une plaque plane, dans des espaces annulaires et le long de faisceaux tubulaires pour une répartition exponentielle du flux de chaleur en écoulement forcé, laminaire ou turbulent," Thèse de Doctorat d'État Es Sciences Physiques, Faculté des Sciences de Paris.

Gräber, H., 1969, "Der wärmeübergang bei der laminar längs angeströmten ebenen plate mit der wärmeflussverteilung $q_{w} \sim x^{m}$," Int. J. Heat Mass transfer, 12, 1605-1620.

https://doi.org/10.1016/0017-9310(69)90095-7

Gräber, H. 1970, "Der wärmeübergang in glaten rohren, zwischen parallelen platen, in ringspalten und längs Rohrbündeln bei exponentieller wärmeflussverteilung in erzwungener laminarer oder turbulenter strömung," Int. J. Heat Mass Transfer, 13, 1645-1703. https://doi.org/10.1016/0017-9310(70)90095-5

Grigull, U., 1956, "Wärmeübergang an nicht-Newtonsche flüssigkeiten bei laminarer rohrströmung," Chem. Ing. Tech., 28, 553-556. https://doi.org/10.1002/cite.330280808

Haji-Sheikh, A., 2009, "Determination of heat transfer in ducts with axial conduction by variational calculus," J. Heat Transfer, 131, 1-11.

https://doi.org/10.1115/1.3122776

Haji-Sheikh, A., Beck, J.V., and Amos, D.E., 2009, "Axial heat conduction effects in the entrance region of circular ducts," Heat Mass Transfer, 45, 331-341.

https://doi.org/10.1007/s00231-008-0432-2

Jambal, O., Shigechi, T., Davaa, G., and Momoki, S., 2005, "Effects of viscous dissipation and fluid axial heat conduction on heat transfer for non-Newtonian fluids in ducts with uniform wall temperature, Part I: Parallel-plates and circular ducts," Int. Comm. Heat Mass Transfer, 32, 1165-1173.

https://doi.org/10.1016/j.icheatmasstransfer.2005.07.002

Jambal, O., Shigechi, T., Davaa, G., and Momoki, S., 2005, "Effects of viscous dissipation and fluid axial heat conduction on heat transfer for non-Newtonian fluids in ducts with uniform wall temperature, Part II: Annular ducts," Int. Comm. Heat Mass Transfer, 32, 1174-1183. $\underline{\text { https://doi.org/10.1016/j.icheatmasstransfer.2005.07.003 }}$

Khatyr, R., and Il Idrissi, A., 2010, Analytic solutions for the forced convection flow of Herschel-Bulkely fluid in a circular duct with variable wall heat flux," Phys. Chem. New., 55, 38-42.
Khatyr, R., Khalid Naciri, J., and Il Idrissi, A., 2016, "Effects viscous dissipation on the asymptotic behaviour of laminar forced convection for Herschel-Bulkley fluid in a circular duct," J. Mech. Eng. Automation, 6, 419-426.

https://doi.org/10.17265/2159-5275/2016.08.005

Khatyr, R., Khalid Naciri, J., and Il Idrissi, A., 2017, "Fully developed laminar forced convection in a circular duct for Herschel-Bulkley fluids with viscous dissipation and axial heat conduction," J. Heat Transfer, 139(10):104504-104504-5. https://doi.org/10.1115/1.4036690

Khatyr, R., Ouldhadda, D., and Il Idrissi, A., 2003, "Viscous dissipation effects on the asymptotic behaviour of laminar forced convection for Bingham plastics in circular ducts," Int. J. Heat Mass Transfer, 46, 589598.

https://doi.org/10.1016/S0017-9310(02)00331-9

Magyari, E., and Barletta, A., 2007, "Analytical series solution for the fully developed forced convection duct flow with frictional heating and variable viscosity," Heat Mass Transfer, 44, 251-259.

https://doi.org/10.1007/s00231-007-0242-y

Mandapati, M.J.K., 2016, "Effect of axial conduction and viscous dissipation on heat transfer for laminar flow through a circular pipe," Perspectives in Science, 8, 61-65.

https://doi.org/10.1016/j.pisc.2016.03.008

Min, T., Yoo, J.Y., and Choi, H., 1997, "Laminar convective heat transfer of a Bingham plastic in a circular pipe- I. Analytical approach- thermally fully developed flow and thermally developing flow (the Graetz problem extended)," Int. J. Heat Mass Transfer, 40, 3025-3037. https://doi.org/10.1016/S0017-9310(96)00362-6

Min, T., Choi, H.G., Yoo, J.Y., and Choi, H., 1997, "Laminar convective heat transfer of a Bingham plastic in a circular pipe- II. Numerical approach- hydrodynamically developing flow and simultaneously developing flow," Int. J. Heat Mass Transfer, 40, 3689-3701.

https://doi.org/10.1016/S0017-9310(97)00004-5

Mishra, A., Pandey, A.K., and Kumar, M., 2018, "Ohmic-viscous dissipation and slip effects on nanofluid flow over a stretching cylinder with suction/injection," Nanoscience and Technology: An International Journal 9 (2), 99-115.

http://doi.org/10.1615/NanoSciTechnolIntJ.2018025410

Mishra, A., Pandey, A.K., and Kumar, M., 2019, "Velocity, thermal and concentration slip effects on MHD silver-water nanofluid past a permeable cone with suction/injection and viscous-Ohmic dissipation," Heat Transfer Research, 50 (14), 1351-1367.

http://doi.org/10.1615/HeatTransRes.2018020420

Nagaraju, G., Garvandha, M., and Murthy, J.V.R., 2019, "MHD flow in a circular horizontal pipe under heat source/sink with suction/injection on wall," Frontiers in Heat and Mass Transfer, 13 (6), 1-8. http://doi.org/10.5098/hmt.13.6

Nouar, C., Devienne, R. et Lebouché, M., 1994, “Convection thermique pour un fluide de Herschel-Bulkley dans la région d'entrée d'une conduite, " Int. J. Heat Mass Transfer, 37, 1-12.

https://doi.org/10.1016/0017-9310(94)90157-0

Pandey, A.K., and Kumar, M., 2017, "Boundary layer flow and heat transfer analysis on $\mathrm{Cu}$-water nanofluid flow over a stretching cylinder with slip," Alexandria Eng. J. 56 (4), 671-677.

http://doi.org/10.1016/j.aej.2017.01.017

Pandey, A.K., and Kumar, M., 2018, "MHD flow inside a stretching/shrinking convergent/divergent channel with heat generation/absorption and viscous-Ohmic dissipation utilizing $\mathrm{Cu}-$ water 
nanofluid," Computational Thermal Sciences: An International Journal 10(5), 457-471.

http://doi.org/10.1615/ComputThermalScien.2018020807

Piva, S., 1995, “An analytical approach to fully developed heating of laminar flows in circular pipes," Int. Comm. Heat Mass Transfer, 22, 815-824.

https://doi.org/10.1016/0735-1933(95)00074-7

Piva, S., and Pagliarini, G., 1994, "Estimation of unknown parameters from exponential heating of laminar flow," Experimental Thermal and Fluid Science, 8, 21-27.

https://doi.org/10.1016/0894-1777(94)90069-8

Sabry, M.N., 2017, "Analytic modeling of laminar forced convection in a circular duct for arbitrary boundary conditions and inlet temperature profile," Int. J. Heat Mass Transfer, 112, 933-939.

https://doi.org/10.1016/j.ijheatmasstransfer.2017.04.129

Sankad, G.C., and Patil, A., 2018, "Heat transfer inferences on the Herschel Bulkley fluid flow under peristalsis," Frontiers in Heat and Mass Transfer, 10 (17), 1-8.

http://doi.org/10.5098/hmt.10.17

Sayed-Ahmed, M.E., and Kishk, K.M., 2008, "Heat transfer for Herschel-Bulkley fluids in the entrance region of a rectangular duct," Int. Comm. Heat Mass Transfer, 35, 1007-1016.

https://doi.org/10.1016/j.icheatmasstransfer.2008.05.002

Singh, P., Pandey, A.K., and Kumar, M., 2016, "Forced convection in MHD slip flow of alumina water nanofluid over a flat plate," Journal of Enhanced Heat Transfer, 23(6), 487-497.

http://doi.org/10.1615/JEnhHeatTransf.2018025485

Singh, K., Pandey, A.K., and Kumar, M., 2019, “Analytical approach to a stagnation point flow and heat transfer of a micropolar fluid via a permeable shrinking sheet with slip and convective boundary conditions," Heat Transfer Research, 50 (8), 739-756.

http://doi.org/10.1615/HeatTransRes.2018024647

Yang, M., Wang, X., Wang, Z., Li, Z., and Zhang, Y, 2018, “Correlation for turbulent convection heat transfer in elliptical tubes by numerical simulations," Frontiers in Heat and Mass Transfer, 11 (7), 1-6. http://doi.org/10.5098/hmt.11.7

Zanchini, E., 1997, "Effect of viscous dissipation on the asymptotic behaviour of laminar forced convection in circular tubes," Int. J. Heat Mass Transfer, 40, 169-178.

https://doi.org/10.1016/S0017-9310(96)00076-2

Zhang, W., Yang, M., and Zhang, W., 2019, "Numerical study of periodically fully-developed flow and heat transfer in channels with periodic semi- circular tube," Frontiers in Heat and Mass Transfer, 12 (18), 1-8.

http://doi.org/10.5098/hmt.12.18

\section{APPENDIX}

The integration of Eq. (19) taking into account the continuity of $f(R)$ at $R=a$ and the vanishing bulk value of $f(R)$ gives :

\section{If $\boldsymbol{m} \in \mathbb{N}^{*}:$}

$$
f(R)=\left\{\begin{array}{l}
\frac{1}{\omega}\left\{\left(\frac{1}{2^{n+1}}+\frac{1}{2(1-a)^{n+1}}\left(\frac{m+1}{\omega}\right)^{n} B r_{\infty}\right) R^{2}-\right. \\
\frac{a}{(m+2)(1-a)^{n}}\left(\frac{m+1}{\omega}\right)^{n} B r_{\infty}\left(\frac{R-a}{1-a}\right)^{m+2}- \\
\frac{(1-a)^{2}}{m+3}\left[\left(\frac{2^{1-n}}{m+2}+\frac{1}{(1-a)^{n+1}}\left(\frac{m+1}{\omega}\right)^{n} B r_{\infty}\right)\left(\frac{R-a}{1-a}\right)^{m+3}-\right. \\
\frac{2^{1-n}}{(m+2)(1-a)^{m+3}}\left(\sum_{k=0}^{m+2}\left(\frac{(m+3) !(-1)^{k} a^{k}}{k !(m+3-k) !} \frac{R^{m+3-k}}{m+3-k}\right)+\right. \\
\left.\left.\left.(-1)^{m+3} a^{m+3} \ln (R)\right)\right]\right\}+C_{1} \quad \text { if } \quad a \leq R \leq 1 \\
\frac{1}{\omega}\left[\frac{1}{2^{n+1}}+\frac{1}{2(1-a)^{n+1}}\left(\frac{m+1}{\omega}\right)^{n} B r_{\infty}\right] R^{2}+\quad \text { if } \quad 0 \leq R \leq a \\
\frac{2^{1-n}}{\omega} \frac{a^{m+3}}{(m+2)(m+3)(1-a)^{m+1}}\left[\sum_{k=0}^{m+2}\left(\frac{(m+3) !(-1)^{k}}{k !(m+3-k) !(m+3-k)}\right)+\right. \\
\left.(-1)^{m+3} \ln (a)\right]+C_{1} \quad \text { if }
\end{array}\right.
$$

Where

$C_{1}=\frac{1}{(m+2)(m+3) \omega^{2}}\{2(m+1)(1-$

a) $)^{2}\left[\frac{1}{(1-a)^{n+1}}\left(\frac{m+1}{\omega}\right)^{n} B r_{\infty}\left(\frac{a^{2}}{2(m+2)}+\frac{a(1-a)}{m+4}+\frac{(m+2)(1-a)^{2}}{2(m+3)(m+5)}\right)+\right.$

$\left.\frac{1}{2^{n}}\left(\frac{2 a}{(m+4)(2 m+5)}+\frac{1-a}{(m+3)(m+5)}\right)\right]-\left(\frac{1}{2^{n}}+\right.$

$\left.\frac{1}{(1-a)^{n+1}}\left(\frac{m+1}{\omega}\right)^{n} B r_{\infty}\right)\left[\frac{(m+2)(m+3)}{4}-(1-a)(3 a+m+\right.$

$\left.\left.\frac{6(1-a)^{2}(m+4+a)}{(m+4)(m+5)}\right)\right]-\frac{2^{2-n}}{(1-a)^{m+1}}\left[(-1)^{m+3} a^{m+3}\left(\frac{a^{2}-1}{4}+\frac{(1-a)^{2}}{(m+2)(m+3)}(1+\right.\right.$

$\left.\left.\frac{(-1)^{m+3} \ln (a)}{(1-a)^{m+3}}\right)\right)+\sum_{k=0}^{m+2} \frac{(m+3) !(-1)^{k} a^{k}}{k !(m+3-k) !(m+3-k)}\left(\frac{2+(m+3-k) a^{m+5-k}}{2(m+5-k)}-\right.$

$\left.\left.\left.\frac{1}{(1-a)^{m+1}}\left[\frac{(-1)^{m+3} a^{m+3}}{(m+2)(m+3)}+\sum_{p=0}^{m+1}\left(\frac{(m+1) !(-1)^{p} a^{p}}{p !(m+1-p) !} \frac{1-a^{2 m+6-k-p}}{2 m+6-k-p}\right)\right]\right)\right]\right\}$

$f(1)=\frac{1}{2^{n+1} \omega}+\frac{B r_{\infty}}{2} \frac{1}{(1-a)^{n+1}}\left(\frac{m+1}{\omega}\right)^{n}-\frac{2^{1-n}}{\omega} \frac{(1-a)^{2}}{(m+2)(m+3)}[1-$

$\left.\frac{1}{(1-a)^{m+3}} \sum_{k=0}^{m+2} \frac{(m+3) !(-1)^{k} a^{k}}{k !(m+3-k) !(m+3-k)}\right]+C_{1}$

and If $\underline{\boldsymbol{m} \in \mathbb{Q}^{*}}$ :

$f(R)=\left\{\begin{array}{l}\frac{1}{\omega}\left\{\left(\frac{1}{2^{n+1}}+\frac{1}{2(1-a)^{n+1}}\left(\frac{m+1}{\omega}\right)^{n} B r_{\infty}\right) R^{2}-\right. \\ \frac{a}{(m+2)(1-a)^{n}}\left(\frac{m+1}{\omega}\right)^{n} B r_{\infty}\left(\frac{R-a}{1-a}\right)^{m+2}- \\ \frac{(1-a)^{2}}{m+3}\left[\left(\frac{2^{1-n}}{m+2}+\frac{1}{(1-a)^{n+1}}\left(\frac{m+1}{\omega}\right)^{n} B r_{\infty}\right)\left(\frac{R-a}{1-a}\right)^{m+3}-\right. \\ \left.\left.\frac{2^{1-n}}{(m+2)(1-a)^{m+3}} \sum_{k=0}^{\infty}\left(\frac{P(m+3-k)(-1)^{k} a^{k}}{k !(m+3-k)^{2}} R^{m+3-k}\right)\right]\right\} \\ +C_{1} \quad \text { if } \quad a \leq R \leq 1 \\ \frac{1}{\omega}\left[\frac{1}{2^{n+1}}+\frac{1}{2(1-a)^{n+1}}\left(\frac{m+1}{\omega}\right)^{n} B r_{\infty}\right] R^{2}+ \\ \frac{2^{1-n}}{\omega} \frac{a^{m+3}}{(m+2)(m+3)(1-a)^{m+1}} \sum_{k=0}^{\infty} \frac{P(m+3-k)(-1)^{k}}{k !(m+3-k)^{2}} \\ +C_{1} \quad \text { if } \quad a \leq R \leq 1\end{array}\right.$

where 
$C_{1}=\frac{1}{(m+2)(m+3) \omega^{2}}\{2(m+1)(1-$

$a)^{2}\left[\frac{1}{(1-a)^{n+1}}\left(\frac{m+1}{\omega}\right)^{n} B r_{\infty}\left(\frac{a^{2}}{2(m+2)}+\frac{a(1-a)}{m+4}+\frac{(m+2)(1-a)^{2}}{2(m+3)(m+5)}\right)+\right.$ $\left.\frac{1}{2^{n}}\left(\frac{2 a}{(m+4)(2 m+5)}+\frac{1-a}{(m+3)(m+5)}\right)\right]-\left(\frac{1}{2^{n}}+\right.$

$\left.\frac{1}{(1-a)^{n+1}}\left(\frac{m+1}{\omega}\right)^{n} B r_{\infty}\right)\left[\frac{(m+2)(m+3)}{4}-(1-a)(3 a+m+\right.$ $\left.\left.\frac{6(1-a)^{2}(m+4-a)}{(m+4)(m+5)}\right)\right]-$

$\frac{2^{2-n}}{(1-a)^{m+1}}\left[\sum_{k=0}^{\infty} \frac{P(m+3-k)(-1)^{k} a^{k}}{k !(m+3-k)^{2}}\left(\frac{2+(m+3-k) a^{m+5-k}}{2(m+5-k)}-\right.\right.$

$\left.\left.\left.\frac{1}{(1-a)^{m+1}} \sum_{p=0}^{\infty}\left(\frac{P(m+1-p)(-1)^{p} a^{p}}{p !(m+1-p)} \frac{1-a^{2 m+6-k-p}}{2 m+6-k-p}\right)\right)\right]\right\}$ $f(1)=\frac{1}{2^{n+1} \omega}+\frac{B r_{\infty}}{2} \frac{1}{(1-a)^{n+1}}\left(\frac{m+1}{\omega}\right)^{n}-\frac{2^{1-n}}{\omega} \frac{(1-a)^{2}}{(m+2)(m+3)}[1-$ $\left.\frac{1}{(1-a)^{m+3}} \sum_{k=0}^{\infty} \frac{P(m+3-k)(-1)^{k} a^{k}}{k !(m+3-k)^{2}}\right]+C_{1}$ where

$\forall m$, if $k=0$ then $P(m)=m$ if $k \geq 1$ then $P(m-k)=(m-k) P(m-(k-1))$ 